\title{
Does Acupressure Help Reduce Nausea and Vomiting in Palliative Care Patients? - A double blind randomised controlled trial
}

Paul Perkins ${ }^{1,2}$; Anne Parkinson²; Rebecca Parker²; Alison Blaken³; Ralph K. Akyea ${ }^{4}$

${ }^{1}$ Gloucestershire Hospitals NHS Foundation Trust, Cheltenham, UK

2 Sue Ryder Leckhampton Court Hospice, Cheltenham, UK

${ }^{3}$ St Elizabeth Hospice, Ipswich, UK

${ }^{4}$ Division of Primary Care, University of Nottingham, Nottingham, UK

\section{Corresponding author:}

Dr Paul Perkins

Chief Medical Director - Sue Ryder AND

Consultant in Palliative Medicine

Gloucestershire Hospitals NHS Foundation Trust and

Sue Ryder Leckhampton Court Hospice

Church Road

Cheltenham

GL53 0QJ

Tel: 01242230199

Fax: 01242224776

Email: paul.perkins@suerydercare.org

\section{KEYWORDS:}

Nausea, vomiting, acupuncture therapy, acupressure WORD COUNT 2,175 


\begin{abstract}
Introduction

Nausea and vomiting are common symptoms for patients with advanced cancer. While there is evidence for acupuncture point stimulation for treatment of these symptoms for patients having anti-cancer treatment there is little for when they are not related to such treatment.
\end{abstract}

\title{
Objective
}

To determine whether acupressure at the Pericardium 6 site can help in the treatment of nausea and vomiting suffered by palliative care patients with advanced cancer.

\section{Materials and methods}

Double blind randomised controlled trial - active versus placebo acupressure wristbands.

In-patients with advanced cancer in two specialist palliative care units who fitted either or both of the following criteria were approached:

Nausea that was at least moderate

Vomiting daily on average for the prior three days

\section{Results}

57 patients were randomised to have either active or placebo acupressure wristbands. There was no difference in any of the outcome measures between the 2 groups:

- Change from baseline number of vomits

- Visual Analogue Scale for 'did acupressure wristbands help you to feel better?'

- Total number of as needed doses of anti-emetic medication

- Need for escalation of anti-emetics

\section{Conclusions:}

In contrast to a previously published feasibility study, active acupressure wristbands were no better than placebo for specialist palliative care in-patients with advanced cancer and nausea and vomiting. 


\section{INTRODUCTION}

Nausea and vomiting are problems for up to $70 \%$ of patients with advanced cancer ${ }^{1}$. Management of these patients rests on trying to treat any underlying cause. If this is not possible, and whilst the underlying cause is being treated, anti-emetics are used. Careful patient assessment allows clinicians to choose an appropriate first-line anti-emetic ${ }^{2}$ based on what is thought to be the underlying neuropharmacological mechanism. While this is a widespread approach there is little evidence for the drugs commonly used for these symptoms in this patient group ${ }^{3,4}$. A recent study has challenged whether this mechanistic approach is correct and whether symptom control could be just as good using one drug 5 .

Acupuncture originated in China over 2000 years ago and is now used globally. It is a technique where needles are inserted in predetermined areas (or acupuncture points) in the body. For nausea, while many acupuncture points have been described for prevention or treatment of nausea, the most commonly described is P6 (Pericardium 6) 6 . This point is located 2 cun (a Chinese measurement equal to approximately $3 \mathrm{~cm}$ ) proximal to the midpoint of the transverse crease of the wrist between the tendons of palmaris longus and flexor carpi radialis. There is mixed evidence for acupuncture point stimulation for control of nausea in pregnancy ${ }^{7}$ and post-operative nausea ${ }^{8}$. For patients with cancer, the majority of studies relate to chemotherapy ${ }^{9,10}$ or radiotherapy ${ }^{11,12}$. Acupressure is an attractive alternative to acupuncture involving pressure on acupuncture points ${ }^{13}$. There is methodological heterogeneity for randomised controlled trials of acupressure and when sham acupressure is used there are a number of alternatives for the sham intervention including acupressure at non-acupuncture points or sham acupressure at real points ${ }^{14}$.

In a large study of patients with chemotherapy-induced nausea, patients were randomised to active wristbands, sham wristbands, or no wristband. Patients in all 
groups received anti-emetics. Both sets of wristbands were elasticated with a small stud which could apply pressure to an acupuncture point. In the active group, this would be placed at P6, in the sham group the bands were placed so that the stud faced outward, not putting pressure on P6. In this large study 500 patients were randomised. There were no statistical differences between the outcomes for the groups although slightly less nausea in the active and sham groups combined when compared with no band ${ }^{15}$, and slightly lower healthcare costs for those who had bands ${ }^{16}$.

We wished to see whether acupressure wristbands placed at the P6 site can help patients with terminal cancer who are suffering from nausea and vomiting. There are a number of reasons why acupressure would be a useful choice for such patients if it helped their symptoms. Firstly, it is relatively easy to apply. Patients (or their carers if they were too fatigued) can place the bands after receiving simple instruction allowing them some control over treatment. Secondly, this can be done at home without the need for a trip to the hospital or hospice for medication. Thirdly, this technique can be used safely in patients with clotting disorders, thrombocytopenia and neutropenia when acupuncture would be contraindicated. Fourthly, it is a technique which is extremely well tolerated. Very few patients have side-effects from wearing the bands and those who do complained only of sensations of tightness, swollen hands and itchy wrists ${ }^{17}$ although blistering at the site of the stud has been reported ${ }^{18}$. We know of no reports of serious adverse effects of acupressure in patients.

There have been very few investigations of acupressure wristbands for cancer patients where the cause of the nausea has not been chemotherapy or radiotherapy ${ }^{19,20}$ and only one randomised trial ${ }^{21}$. In this small feasibility study 10 patients were randomised to active or placebo acupressure wristbands. That study allowed power calculations to inform the study presented here. As in the feasibility study, patients were allowed antiemetics alongside the acupressure intervention. 


\section{PATIENTS, MATERIALS AND METHODS}

Between 17.06.10 and 01.01.18 adult in-patients at two Specialist Palliative Care Units were approached if they met the following inclusion criteria:

1. Diagnosis of advanced cancer with an estimated prognosis of less than 1 year but more than 3 days.

2. Nausea as at least moderate on a none/mild/moderate/severe scale OR had at least one vomit per day for the last three days.

3. Have an underlying cause for their nausea thought to be irreversible OR the patient has made an autonomous choice not to proceed with treatment for any potentially reversible cause (for example surgery for bowel obstruction or drainage of ascites).

4. If patients are taking corticosteroids the dosage should be stable for 3 days before and during the trial.

\section{Exclusion criteria}

1. Arm lymphoedema.

2. Weakness, fatigue or confusion sufficient that patient is unable to take part.

3. Previous history of acupuncture/acupressure for nausea or vomiting, or history of use of acupressure by a close relative.

4. History of Parkinsonism or Parkinsonism on examination (as metoclopramide included in treatment escalation schedule for patients with suspected gastric stasis)

5. Sharing a room with another patient taking part in the study.

6. Unable to read or comprehend the questionnaires or Visual Analogue Scale (VAS). 
If patients were positive about participation the study was described to them by a member of the research team and a patient information leaflet given to them. They were given a minimum of 1 hour to consider participation. If after this time they were happy to proceed they were asked to sign a consent form.

A baseline assessment was then completed by a member of the research team documenting the likely clinical picture or cause for nausea. The patient was asked to complete a baseline VAS nausea rating.

Pairs of active or placebo acupressure wristbands had previously been placed in sequential numbered envelopes according to a sequence derived from randomization.com. The bands were provided free of charge by Sea-Band Ltd. They appeared the same when in place, the difference being that active bands have a spherical bead exerting pressure while sham bands have no such bead. The bands were placed on participants' wrists at the correct P6 points by a member of the research team not involved with clinical decision making for the patient.

Patients' anti-emetics were not altered on Day 0 and they continued their current antiemetic regimen which could be as needed, regular oral or subcutaneous medication, or a constant infusion via subcutaneous syringe driver.

For the next 3 days the patient was assessed by a clinician (blinded to the type of acupressure bands in place) and asked if the patient felt that their nausea / vomiting control was good enough. If not, the clinician could escalate the patient's anti-emetics according to a pre-defined treatment escalation schedule. This schedule took account of the most likely clinical picture. If regular oral anti-emetics did not give adequate symptom control patients were offered a constant infusion via a subcutaneous syringe driver. In-patient unit nursing staff reminded patients to complete their daily nausea assessments and estimate of efficacy. Patient participation in the study finished on Day 
3. Wristbands were then removed, and patients had the option of wearing a normal pair of acupressure wristbands if they wished.

\section{Outcome Measures:}

Primary outcome measures were determined by the feasibility study:

- Change from baseline number of vomits

- VAS for 'did acupressure wristbands help you to feel better?'

- Total number of as needed doses of anti-emetic medication

- Need for escalation of anti-emetics

Secondary outcome measures were:

- VAS of nausea measured daily.

- Duration of perceived nausea over previous 24 hours.

- Adverse effects of acupressure.

\section{Statistical Analysis}

Descriptive statistics were used to characterise the cohort. The frequency with percentages are reported for categorical outcome measures and median with interquartile range values are reported for the continuous variable outcome measures. The non-parametric Mann-Whitney $U$ and Fisher's test were used to compare outcomes. 


\section{RESULTS}

57 patients were recruited to the study (30 in the active arm and 27 in the placebo arm).

Two patients in the active arm became too unwell before they could contribute any data so they have not been included in analysis. For CONSORT Diagram see Figure 1 and baseline characteristics see Table 1. Patients in the placebo arm had a higher average baseline nausea VAS but this was not of statistical significance. There was no difference between the numbers of patients receiving oral medication or via a syringe driver but there were more patients in the active arm receiving injections of anti-emetics.

Table 1. Baseline characteristics

\begin{tabular}{|c|c|c|c|}
\hline & $\begin{array}{c}\text { Active } \\
(n=28)\end{array}$ & $\begin{array}{c}\text { Placebo } \\
(n=27)\end{array}$ & $p$-value \\
\hline Age, years; median (IQR) & $65.5(57.5-75.0)$ & $67.0(59.0-71.0)$ & 0.743 \\
\hline Females & $24(85.7)$ & 24 (88.9) & 0.724 \\
\hline Diagnosis & & & \multirow{8}{*}{0.615} \\
\hline Upper Gastrointestinal Tract & 4 & 6 & \\
\hline Lower Gastrointestinal Tract & 3 & 4 & \\
\hline Pancreas / gall bladder & 6 & 4 & \\
\hline Lung & 6 & 4 & \\
\hline Ovary & 3 & 5 & \\
\hline Breast & 2 & 2 & \\
\hline Other & 4 & 2 & \\
\hline \multicolumn{3}{|l|}{ Nausea level } & \multirow{5}{*}{0.970} \\
\hline None & $4(14.3)$ & $5(18.5)$ & \\
\hline Mild & $7(25.0)$ & $7(25.9)$ & \\
\hline Moderate & $14(50.0)$ & $12(44.4)$ & \\
\hline Severe & $3(10.7)$ & $3(11.1)$ & \\
\hline Baseline Nausea VAS, median (IQR) & $28.5(12.5-56.5)$ & $38.5(13.0-58.0)$ & 0.580 \\
\hline Pattern of nausea None-mild & $8(28.6)$ & $6(22.2)$ & \multirow{6}{*}{$\begin{array}{l}0.589 \\
0.221 \\
0.912 \\
0.646 \\
0.092 \\
0.358\end{array}$} \\
\hline And associated & $20(71.4)$ & $15(55.6)$ & \\
\hline symptoms & & & \\
\hline Movement-related & $11(36.3)$ & $11(40.7)$ & \\
\hline Obstructive & $11(36.3)$ & $9(33.3)$ & \\
\hline Medication cause & 5 (17.9) & $1(3.7)$ & \\
\hline
\end{tabular}




\begin{tabular}{|c|c|c|c|}
\hline Regular Antiemetic at baseline None & 2 & 0 & \\
\hline Cyclizine & 6 & 7 & \\
\hline Metoclopramide & 17 & 14 & \\
\hline Haloperidol & 13 & 18 & \\
\hline Levomepromazine & 23 & 19 & \\
\hline Ondansetron & 3 & 0 & \\
\hline \multicolumn{4}{|l|}{ Route of anti-emetic administration } \\
\hline $\mathrm{PO}$ & 25 & 20 & 0.551 \\
\hline SC injection & 38 & 17 & 0.001 \\
\hline $\mathrm{CSCl}$ & 16 & 23 & 0.098 \\
\hline Regularity & & & \multirow{6}{*}{0.433} \\
\hline PRN only & 2 & 0 & \\
\hline OD & 2 & 4 & \\
\hline TDS & 8 & 4 & \\
\hline $\mathrm{CSCl}$ & 16 & 23 & \\
\hline$B D$ & 0 & 1 & \\
\hline
\end{tabular}

Results for primary and secondary outcome measures are in Table 2 and 3 respectively. For each of days $1-3$ there was no difference between the groups with regard to any of the outcome measures.

The main adverse event was that the bands felt too tight and this led to one patient in each arm withdrawing from the study before day 3. Levels of missing data varied from 4.4 to $15.1 \%$ for different outcome measures.

Table 2 - Primary Outcome Measures

Results for interventions

\begin{tabular}{|c|c|c|c|c|}
\hline & & $\begin{array}{l}\text { Active } \\
(\mathrm{n}=28)\end{array}$ & $\begin{array}{l}\text { Placebo } \\
(n=27)\end{array}$ & $p$-value \\
\hline Total number of study days & & 84 & 75 & 0.940 \\
\hline & Day 1 & 28 & 27 & \\
\hline & Day 2 & 28 & 24 & \\
\hline & Day 3 & 28 & 24 & \\
\hline $\begin{array}{l}\text { Average number of vomits at baseline } \\
\text { (previous } 3 \text { days), median (IQR) }\end{array}$ & & $2(1-3)$ & $2(1-3)$ & 0.9112 \\
\hline
\end{tabular}




\begin{tabular}{|c|c|c|c|}
\hline $\begin{array}{l}\text { Average number of vomits during 3-day study } \\
\text { period, median (IQR) }\end{array}$ & $1.2(0.5-1.8)$ & $0.7(0.3-2.0)$ & 0.5657 \\
\hline Number with missing data on vomits & 4 & 3 & \\
\hline Difference in average number of vomits & $-0.7(-1.7-0)$ & $-0.8(-1.5--0.3)$ & 0.9288 \\
\hline $\begin{array}{l}\text { Do you think the acupressure wristbands } \\
\text { helped you to feel better? } \mathrm{mm} \text {, median (IQR) }\end{array}$ & $35(11-63)$ & $46.5(8-80.5)$ & 0.7528 \\
\hline Day 1 & $47(18.5-73)$ & $30(4-82)$ & 0.4181 \\
\hline No. with missing value & 4 & 2 & \\
\hline Day 2 & $32(6-54)$ & $53(14-87)$ & 0.2199 \\
\hline No. with missing value & 1 & 8 & \\
\hline Day 3 & $43(10-66.5)$ & $52(14-62.5)$ & 0.9861 \\
\hline No. with missing value & 4 & 7 & \\
\hline Total number of PRN doses & 65 & 50 & 0.1317 \\
\hline \multicolumn{4}{|l|}{ Escalation of antiemetic } \\
\hline No & 70 & 60 & \multirow{3}{*}{0.957} \\
\hline Yes & 14 & 13 & \\
\hline Number with missing value & 0 & 2 & \\
\hline
\end{tabular}

Table 3 Secondary Outcome Measures

Results for interventions

\begin{tabular}{|c|c|c|c|}
\hline & $\begin{array}{l}\text { Active } \\
(n=28)\end{array}$ & $\begin{array}{l}\text { Placebo } \\
(n=27)\end{array}$ & $p$-value \\
\hline $\begin{array}{l}\text { Nausea VAS mm (all } 3 \text { days), median } \\
\text { (IQR) }\end{array}$ & $22.5(6.5-58)$ & $21(7-43)$ & 0.5736 \\
\hline Baseline (Day 0) & $28.5(12.5-56.5)$ & $38.5(13.0-58.0)$ & 0.580 \\
\hline Day 1 & $23.5(8-50.5)$ & $28(6-55)$ & 0.9035 \\
\hline No. with missing VAS & 4 & 4 & \\
\hline Day 2 & $24.5(8-55)$ & $17(3-37)$ & 0.21146 \\
\hline No. with missing VAS & 2 & 7 & \\
\hline Day 3 & $18(2-71)$ & $26(7-42)$ & 0.9387 \\
\hline No. with missing VAS & 2 & 5 & \\
\hline $\begin{array}{l}\text { Time nauseated over last } 24 \text { hours } \\
\text { (all } 3 \text { days) }\end{array}$ & & & 0.769 \\
\hline$<1 / 4$ & 42 & 31 & \\
\hline $1 / 4-1 / 2$ & 15 & 17 & \\
\hline $1 / 2-3 / 4$ & 11 & 10 & \\
\hline $3 / 4-1$ & 8 & 8 & \\
\hline No. with missing value & 8 & 9 & \\
\hline
\end{tabular}




\begin{tabular}{rrrrr}
\hline Adverse Event & 15 & 13 & 0.299 \\
\hline Side effect type & & & 0.166 \\
\hline Dug in & 1 & 0 & \\
\hline Giddy & 1 & 0 \\
\hline Itchy & 3 & 0 \\
\hline Tired & 1 & 0 \\
\hline Too tight & 9 & 13 \\
\hline
\end{tabular}

\section{CONCLUSIONS}

This is the first adequately powered randomised controlled trial of active versus placebo acupressure wristbands for nausea and vomiting in a terminally ill palliative care population where the focus was not chemotherapy or radiotherapy. The study took longer to recruit to than hoped. Most patients admitted did not fit the inclusion criteria. The most common reasons were because nausea or vomiting was not severe enough; or that patients did not fit the prognostic criteria. There were different levels of missing data in our study. The reason for missing data was largely when patients became too unwell to complete assessments or misinterpreted how to complete VASs, although there were instances where nurses did not document the number of vomits per day. Missing data is increasingly recognised as a problem in palliative care research ${ }^{22}$. While any missing data is disappointing, levels in this study were lower than those reported in a recent systematic review ${ }^{23}$. It's likely that this was because of a relatively short study over 3 days with outcome measures that are straightforward to complete. Adverse events were not severe and only two patients withdrew because of them. In a recent systematic review examining the role of acupressure for chemotherapyinduced nausea and vomiting, acupressure reduced the severity of acute and delayed nausea ${ }^{24}$. However, in their subgroup analyses non-sham-controlled trials tended towards significance while the sham-controlled trials did not, suggesting that sham 
acupressure had a placebo effect. In another study patients were asked whether they expected wristbands to work and those that did had more chance of an effect, which the authors say may be another pointer to a placebo effect ${ }^{25}$. This and another study showed variable effects of gender on response with one showing better efficacy in men ${ }^{25}$ and another in women ${ }^{15}$.

In our study, there was no evidence of a sham placebo effect as neither group showed an improvement in any of the outcome measures.

So, where does this leave the use of acupressure wristbands for palliative care patients? This study shows that in this hospice in-patient unit population active bands are not better than placebo. It is difficult to argue that medication worked well for this population as symptoms did not improve greatly in either arm. The number of vomits per day decreased in both arms but this did not reach statistical significance. There are some interesting questions which remain. It is unclear whether acupressure would have worked better for one mechanism of nausea and vomiting rather than another (e.g. biochemical nausea rather than gastric stasis). There were not enough patients in each group to be able to ascertain this. Perhaps wristbands would have worked better for less symptomatic patients, e.g. those seen as out-patients or at home. They do not appear to work in this highly symptomatic population. For now, we will advocate the use of wristbands only for those palliative care patients who are keen to try an intervention that does not involve drugs with the explanation that there is little evidence to support their use.

\section{ACKNOWLEDGEMENTS}

We are grateful to the patients and families who participated in this study; and the staff in the two hospice inpatient units who supported it. We would also like to thank the following - Professor Antony Arthur (Protocol development and randomisation), Katie Carpenter (Consultant at Priscilla Bacon Lodge, Norwich - recruitment), Beccy Day (BD - data collection) (Research Nurse), and Camila Garces-Bovett (Librarian at 
Gloucestershire Hospitals NHS Foundation Trust Library \& Knowledge Service Literature search).

\section{CONTRIBUTORS}

PP conceived the study and designed it along with AB. AP collected most of the data along with BD. RKA was responsible for data analysis. All authors contributed to the analysis and interpretation of the data and critically revised drafts of the paper. They also read and approved the final version of the manuscript. PP is the guarantor.

\section{FUNDING}

Sea-Band provided active and placebo wristbands free of charge. The study was funded by Sue Ryder Leckhampton Court Hospice Research Department.

\section{COMPETING INTERESTS}

All authors have completed the Unified Competing Interests form at http://www.icmje.org/coi_disclosure.pdf (available on request from the corresponding author).

\section{APPROVALS/ETHICS}

The study was approved by Gloucestershire Research Support Service, the Sue Ryder Research Governance Group, the National Research Ethics Service Committee East of England - Cambridge East. ClinicalTrials.gov Identifier: NCT00550251

\section{PROVENANCE AND PEER REVIEW}

Not commissioned, externally peer reviewed.

\section{DATA SHARING STATEMENT}

Unpublished data are held by Sue Ryder Leckhampton Court Hospice.

\section{REFERENCES}

1 Harris D. Nausea and vomiting in advanced cancer. Brit Med Bull 2010; 96;1:175-85.

2 Collis E, Mather H. Nausea and vomiting in palliative care. BMJ 2015:h6249.

3 Cox L, Darvill E, Dorman S. Levomepromazine for nausea and vomiting in palliative care. Cochrane Database Syst Rev 2015;11:CD009420. 
4 Murray-Brown F, Dorman S. Haloperidol for the treatment of nausea and vomiting in palliative care patients Cochrane Database Syst Rev 2015; 11:CD006271.

5 Hardy J, Skerman H, Glare P, et al. A randomized open-label study of guideline-driven antiemetic therapy versus single agent antiemetic therapy in patients with advanced cancer and nausea not related to anticancer treatment. BMC Cancer. 2018;18(1). 6 Filshie J, White A Medical Acupuncture: A Western Scientific Approach. $1^{\text {st }}$ ed. Edinburgh: Churchill Livingstone 1998:296.

7 Matthews A, Haas DM, O'Mathúna DP, et al. Interventions for nausea and vomiting in early pregnancy. Cochrane Database Syst Rev 2015; 9: CD007575.

8 Lee A, Chan SKC, Fan LTY. Stimulation of the wrist acupuncture point PC6 for preventing postoperative nausea and vomiting. Cochrane Database Syst Rev 2015; 11 : CD003281.

9 Ezzo J, Richardson MA, Vickers A, et al. Acupuncture-point stimulation for chemotherapy-induced nausea or vomiting. Cochrane Database Syst Rev 2006;2:CD002285

10 Widgren $\mathrm{Y}$, Enblom A. Emesis in patients receiving acupuncture, sham acupuncture or standard care during chemo-radiation: A randomized controlled study. Complement Ther Med. 2017;34:16-25.

11. Enblom A, Johnsson A, Hammar M, et al. Acupuncture compared with placebo acupuncture in radiotherapy-induced nausea-a randomized controlled study. Ann Oncol. 2012;23:1353-61.

12. Asadpour R, Kessel K, Habermehl D, et al. EP-1418: RandOmized Study Exploring the combination of radioTherapy with Two types of Acupuncture treatment. Radiother Oncol. 2017;123:S758.

13 Filshie J, White A Medical Acupuncture: A Western Scientific Approach. $1^{\text {st }}$ ed. Edinburgh: Churchill Livingstone1998:29. 
14 Tan J, Suen L, Wang T, Molassiotis A. Sham Acupressure Controls Used in Randomized Controlled Trials: A Systematic Review and Critique. PLOS ONE.2015;10:e0132989.

15 Molassiotis A, Russell W, Hughes J, et al. The Effectiveness of Acupressure for the Control and Management of Chemotherapy-Related Acute and Delayed Nausea: A Randomized Controlled Trial. J Pain Symptom Manage 2014;47:12-25.

16 Molassiotis A, Russell W, Hughes J, et al. The effectiveness and cost-effectiveness of acupressure for the control and management of chemotherapy-related acute and delayed nausea: Assessment of Nausea in Chemotherapy Research (ANCHoR), a randomised controlled trial. Health Technol Assess 2013;17(26) 17 Duggal K, Douglas M, Peter E, et al. Acupressure for intrathecal narcotic-induced nausea and vomiting after caesarean section. Int J Obstet Anesth 1998;7:231-6.

18 Alkaissi A, Evertsson K, Johnsson V, et al. P6 acupressure may relieve nausea and vomiting after gynecological surgery: an effectiveness study in 410 women. Can J Anesth 2002;49:1034-9.

19 Brown S, North D, Marvel FK, et al. Acupressure wrist bands to relieve nausea and vomiting in hospice patients: do they work? Am J Hosp Palliat Care 1992;9:26-9. 20 Wright $L$. The use of motion sickness bands to control nausea and vomiting in a group of hospice patients. Am J Hosp Palliat Care 2005;22:49-53.

21 Perkins $\mathrm{P}$, Vowler S. Does acupressure help reduce nausea and vomiting in palliative care patients? Pilot study. Palliat Med 2008;22:193-4.

22 Hussain J, White I, Langan D, et al. Missing data in randomized controlled trials testing palliative interventions pose a significant risk of bias and loss of power: a systematic review and meta-analyses. J Clin Epidemiol 2016;74:57-65. 
23 Hussain J, Bland M, Langan D, et al. Quality of missing data reporting and handling in palliative care trials demonstrates that further development of the CONSORT statement is required: a systematic review. J Clin Epidemiol 2017;88:81-91. 24 Miao J, Liu X, Wu C, et al. Effects of acupressure on chemotherapy-induced nausea and vomiting-a systematic review with meta-analyses and trial sequential analysis of randomized controlled trials. Int J Nurs Stud 2017;70:27-37.

25 Roscoe J, Morrow G, Hickok J, et al. The Efficacy of Acupressure and Acustimulation Wrist Bands for the Relief of Chemotherapy-Induced Nausea and Vomiting. J Pain Symptom Manage 2003;26:731-742. 